\title{
Mídia-Educação - entre a teoria e a prática
}

\section{Birgitte Tufte*}

Ole Christensen**

\section{Resumo:}

O artigo inicia focando as discussões atuais sobre a definição de mídia-educação, referindo-se a uma recente conferência internacional. Hoje contamos com perspectivas interessantes em relação às mídias e às crianças. As tecnologias de mídia mudam rapidamente, assim como o uso que as crianças fazem delas, o que lhes traz habilidades que a geração anterior não tinha. Isto desafia a forma e o conteúdo da mídia-educação, bem como todo o currículo escolar. O artigo discute uma abordagem educacional ampla, teórico-prática, ao tema das mídias e da informação. Parte das experiências de cooperação dos autores com professores do sistema escolar dinamarquês, sendo apresentados dois modelos: o primeiro, que tem sido usado há muitos anos em relação aos meios de comunicação tradicionais, como a imprensa, a TV e o vídeo - o chamado modelo em zig-zag. E o segundo, voltado ao ensino no novo contexto multimídia. O primeiro projeto descreve como ensinar sobre cinema em classes do primeiro ao terceiro ano do ensino primário, e o segundo descreve o desenvolvimento de uma ferramenta de cinema para professores, incluindo o que os autores chamam de "modelo tufão", uma segunda versão do modelo em zig-zag. $\mathrm{O}$ artigo conclui com uma discussão sobre o futuro da mídia-educação.

Palavras-chave: Mídia. Tecnologia educacional. Educação - Inovações tecnológicas.

* Doutora em Media Literacy pela Danish University of Education. Professora e pesquisadora da Copenhagen Bussiness School, coordenou inúmeras pesquisas europeias sobre crianças, jovens, mídia e consumo.

** Professor do University College Copenhagen. 
No Congresso Mundial da International Association of Mass Communication Researchers (IAMCR) realizado em julho de 2008 em Estocolmo, a definição de mídia-educação foi discutida em um grupo de trabalho voltado a esse tema específico. Foi espantoso e revelador observar as mudanças de perspectiva em relação ao tema. Assim como em anos anteriores, também nessa ocasião os debates sobre mídia-educação concentraram-se na importância do acesso às mídias a partir de uma perspectiva crítica, na importância da avaliação e da análise em relação ao ensino de mídia-educação. Alguns anos atrás, um termo importante para a discussão nesse campo era "produção de mídia”, ou seja, a ideia de que os estudantes devem aprender a produzir eles mesmos - a trabalhar juntos e de modo cooperativo em processos de produção com o objetivo de criar um bom material, a partir de um olhar interior aos processos de produção e à linguagem das mídias. Hoje, a ênfase no termo "produção de mídia" foi substituída pela ênfase na "criação" especialmente no contexto da "criação de conteúdos digitais".

Ousaríamos dizer que a razão disso é a mudança nas tecnologias de mídia, assim como nos padrões e abordagens políticas delas. Criar o próprio blog, entrar no My Space e compor um perfil no Facebook são todas ações criativas individuais, ou seja, de criação de conteúdo, enquanto a "produção de mídia" refere-se à cooperação com o objetivo de obter um conhecimento profundo de como se comunicar em diferentes mídias - como apresentar uma mensagem - em uma perspectiva democrática. Diante disso, a mídiaeducação escolar tem um desafio especial a enfrentar: partindo de uma educação baseada numa cultura de mídias comercializada e individualista, levá-la a se desenvolver no sentido da formação de comunidades práticas de mídia, cujas palavras-chave sejam: perspectiva crítica, análise, avaliação, criatividade e criação.

\section{Uso das mídias}

As mídias ocupam muito tempo na vida das crianças e dos adultos. Em muitas famílias a sala tornou-se um espaço de atividades onde os jovens parecem capazes de conviver sem problemas, usando cada qual o seu meio de comunicação - gerando aquilo que para muitos adultos é um inferno de sons e imagens. $\mathrm{Na}$ escola, porém, as novas mídias ainda não conseguiram se estabelecer com tanta firmeza. 
As mídias tanto unem como separam as pessoas. Tempo, lugar e espaço mudaram de significado. A paisagem midiática se caracteriza hoje por usos e formas de comunicação complexos e instáveis, em que salas físicas e virtuais atuam lado a lado. As mídias são parte central na vida da chamada Geração Internet. Em uma família comum, as pessoas tendem a passar tempo juntas, muitas vezes em torno da TV, que costuma ser o centro das atenções, especialmente nas noites de sexta-feira ou sábado. A família se aconchega em torno de programas familiares, escolhidos a partir do mínimo denominador comum, enquanto todos comem, bebem e conversam sobre o programa e sobre o que aconteceu na semana anterior. Esse padrão se repete até que as crianças cheguem à puberdade, quando começam a passar mais tempo com os amigos e a usar a TV ou a Internet em seus próprios quartos.

Hoje os padrões de mídia estão mudando. Crianças e jovens clicam de uma mídia para outra, em busca do que os interesse e com esse objetivo usam a mídia que estiver mais a mão: materiais impressos, a televisão, a internet ou o celular. Se olharmos para esses usos das mídias, veremos que eles são complexos, intensivos e especialmente digitalizados e baseados na internet.

As crianças e os jovens usam as mídias de modo convergente e interativo. Por exemplo: a TV pode estar ligada em um canal de música, enquanto o menino joga um videogame ou faz pesquisa para um trabalho escolar na internet ou está conectado ao Messenger, ao Facebook ou ao My Space, comunicando-se com amigos. Além desse uso convergente das mídias, e de que as próprias mídias estão se fundindo, um aspecto interessante é a entrada em cena da Web 2.0.

A $W e b 2.0$ é um novo fenômeno, o nome comum para a criação compartilhada de conteúdos, em novas tecnologias como podcast, vodcast, weblog, wiki e RSS-feeds, entre outros. Isto significa que o conteúdo da Web 2.0 é em grande parte gerado pelos usuários e dá a eles a oportunidade de interagirem. A Web 2.0 é descrita como uma rede social que é ao mesmo tempo uma dinâmica e complexa coleção de informações.

O uso das mídias parece ser uma parte integral do cotidiano de crianças e adolescentes, o que desafia a escola e os professores; desafia também a forma e o conteúdo da mídia-educação - e o próprio currículo escolar (ERSTAD, 2005). 


\section{A barreira entre as gerações}

Hoje presenciamos uma barreira especial entre as gerações. Isso prevalece especialmente no caso das habilidades operacionais das mídias, estando as crianças e os jovens muito à frente dos adultos na experimentação e no uso de computadores e celulares, principalmente em termos de comunicação. Os meninos e as meninas são o pelotão avançado, enquanto pais e professores os assistem cruzar velozmente as novas paisagens midiáticas, tentando alcançá-los (TUFTE, 2005).

No entanto, muitas vezes, quando os jovens colhem informações por meio da internet, por exemplo, têm dificuldades em aferir a credibilidade e a origem do material; em outras palavras, é importante prestarmos atenção na questão pedagógica de que eles muitas vezes não possuem uma perspectiva crítica sobre suas fontes de informação. Eles nem sempre têm consciência da necessidade de obter habilidades práticas sobre o próprio uso das mídias, o que inclui seus aspectos estéticos e analíticos.

É aí que pais e professores entram em cena. Muitos adultos sentemse quase impotentes em relação ao rápido desenvolvimento da paisagem midiática e das atividades que fazem parte dela em que a geração mais jovem exibe tanta competência. Hoje muitos adultos sentem que a cultura digital e internacional das mídias interfere no tempo e nas culturas familiares e tradicionais e consequentemente questiona os valores estabelecidos. Ao mesmo tempo, muitos adultos sentem que as crianças e os jovens apropriamse muito rapidamente das novas tecnologias e atingem uma competência com as mídias muito superior à sua. $\mathrm{O}$ contraste entre as crianças e os adultos em termos das mídias torna-se cada vez mais agudo por uma série de razões. Em primeiro lugar, como foi mencionado, as mídias estão convergindo e a Web 2.0 impõe desafios à educação. Outra perspectiva em relação à barreira entre as gerações liga-se ao fato de as forças do mercado e a globalização das mídias terem um controle cada vez maior sobre os conteúdos midiáticos.

Podemos detectar uma discrepância entre o currículo escolar e o uso cotidiano de mídias. Diferentes gerações desenvolveram diferentes habilidades e competências. As competências culturais e midiáticas das crianças e dos jovens são obtidas durante seu tempo livre, ficando óbvia a ausência de uma abordagem crítica ao uso das mídias, bem como a falta de 
competências críticas, como, por exemplo, quando eles surfam na internet (CHRISTENSEN; TUFTE, 2005).

\section{Como lidar com duas culturas diferentes?}

Como descrevemos acima, existem dois tipos de cultura: uma, a do tempo livre, em que o uso convergente das mídias desempenha um papel crescente; e outra, a cultura escolar, ligada prioritariamente à documentação escrita. Na vida cotidiana, essas duas culturas influenciam-se mutuamente, na socialização cultural e no processo de criação de identidade. É nessa área de tensão que a mídia-educação deveria se desenvolver - tanto em termos de pesquisa quanto de ensino.

A seguir iremos: definir o campo científico da pesquisa e definir o campo educacional da pesquisa.

A mídia-educação definida enquanto um campo de pesquisa situase na área de tensão entre a pesquisa em comunicação e a pesquisa em educação. O trabalho de pesquisa e desenvolvimento no contexto da mídiaeducação concentra-se em: estudar a relação entre crianças, jovens e as mídias, em conexão com sua socialização; estudar e avaliar a mídia-educação de um ponto de vista didático, em relação aos objetivos, conteúdos e áreas de trabalho. Um exemplo é a realização de análises e estimativas contendo perspectivas teóricas, metodológicas e práticas em relação ao trabalho de desenvolvimento mídia-educativo.

Quando falamos em "mídias" estamos incluindo um leque de meios de comunicação, incluindo imprensa, mídias eletrônicas - sons e imagens filmes, e mídias interativas (multimídia). Ao mesmo tempo, estamos lidando com uma área profissional das mídias que deve ser exercida tanto em relação a um único campo como numa dimensão curricular transversal.

Em termos do conteúdo da mídia-educação enquanto campo educacional é comum a distinção entre um ensino das mídias e um ensino que usa as mídias como recurso. Quando os professores ensinam usando as mídias, eles precisam de certo conhecimento prático, combinado com a perspectiva analítica e o conhecimento sobre as linguagens específicas dos meios. No entanto, pode ser difícil distinguir as duas coisas, como, por exemplo, ensinar sobre as mídias e através delas. Idealmente, enquanto professores, deveríamos conseguir relacionar esses dois aspectos ao usar 
as mídias. Por exemplo, se você mostra um filme em idioma estrangeiro, deveria ser natural trabalhar numa perspectiva ao mesmo tempo linguística, cultural e midiática.

Boa parte do trabalho em mídia-educação que vem sendo desenvolvido recentemente na Dinamarca baseia-se em caos, teimosia e determinação bons exemplos da tradição dinamarquesa de trabalho de base, no qual as coisas brotam de baixo para cima. Com base nas experiências feitas até agora não é possível definir uma didática específica para o trabalho com as mídias e, sim, desenvolver abordagens acadêmicas no trabalho transdisciplinar a fim de criar novas formas didáticas - construídas a partir das experiências mídia-educacionais já realizadas (QVORTRUP, 2006).

\section{Um quadro conceitual da Mídia-Educação}

Na Grande Enciclopédia Dinamarquesa (Den Store Danske Encyklopadi, 2009) não é possível encontrar a expressão "mídia-educação", nem "didática dos meios", "pedagogia dos meios" ou "formação para as mídias". Não há uma linha sequer ligada ao tema. Isso pode ser interpretado como evidência de que a área ainda não conseguiu entrar na cultura tradicional que em geral se manifesta em uma enciclopédia. Então, como podemos definir o que é mídia-educação?

Inspirados pela Grande Enciclopédia Dinamarquesa (onde a educação é definida como "o ensino da teoria e da prática em relação aos objetivos, meios, relações e obstáculos no desenvolvimento de valores, conhecimento e competências individuais"), escolhemos definir mídia-educação como um conceito dinâmico que constantemente reflete a conexão entre as crianças, os jovens e os meios de comunicação - durante seu tempo de lazer e nas instituições educacionais - e que se desenvolve na fronteira de tensão entre as práticas, os conhecimentos empíricos e as teorias mídia-educacionais. Estamos lidando com um conceito ainda não determinado por uma dada metodologia, mas que se desenvolve em uma correlação educacional e busca desenvolver uma visão abrangente no interior de seu campo.

E o que é didática das mídias?

Didática das mídias é a parte da mídia-educação que lida com objetivos e conteúdos. Ela envolve o planejamento de aulas com uso de tecnologias de comunicação; contudo, o uso de tecnologias em si, em relação a um 
conteúdo, não é definido como sendo a didática das mídias. O termo mais abrangente nesse caso é pedagogia das mídias, no qual se encontram também todas as outras didáticas acadêmicas. O dilema - se olharmos a história da mídia-educação com foco especial na paisagem das mídias, nas crianças e nas escolas de hoje - é que a escola apoia-se em uma base cultural literária, na qual o objetivo é educar as crianças para serem bons cidadãos críticos em uma sociedade democrática. Mas a escola "paralela" das mídias vê as crianças e os adultos como consumidores em uma sociedade global orientada pela economia de mercado. A tarefa do trabalho mídia-educacional é fazer essas duas partes entrarem em um diálogo a fim de qualificar as crianças a viverem em uma sociedade orientada pelo mercado, porém com objetivos democráticos (TUFTE, 2007).

De modo geral, em relação às mídias, suas estéticas e linguagens, é preciso desenvolver princípios e métodos para que as mídias possam ser inseridas na agenda da escola enquanto um processo de aprendizagem. É preciso que sejam desenvolvidos instrumentos conceituais mídia-educativos em relação a todas as mídias.

Neste sentido, nos inspiramos no projeto de pesquisa inglês $U K$ Children Go Online (LIVINGSTONE; BOVER, 2005) que estuda o uso da internet entre crianças e jovens. Em um relatório intitulado Alfabetiz̧ação ${ }^{1}$ para a Internet entre crianças e jovens (Internet Literacy among Children and Young People) o foco está nos conceitos de "alfabetização midiática e alfabetização para a internet”. A alfabetização para a internet é um processo definido como:

- Acesso: a alfabetização para a internet é um requisito para o acesso tanto aos equipamentos quanto aos conteúdos e serviços online, bem como para regular as condições desse acesso;

- Compreensão: a alfabetização para a internet é crucial para uma avaliação efetiva, criteriosa e crítica das informações e oportunidades online;

- Criação: a alfabetização para a internet permite que o usuário torne-se um ativo produtor, além de um receptor de conteúdos, permitindo a interatividade e a participação online.

Concordamos que essas três perspectivas são centrais se quisermos desenvolver uma plataforma mídia-educativa que abranja a cultura de lazer, 
incluindo os usos gerais de mídia das crianças e dos jovens, bem como a internet, e tendo como objetivo uma conexão entre os usos de mídia no tempo livre e aqueles que ocorrem na escola. Estas perspectivas seguem a mesma linha apresentada no início deste artigo. Seguindo esse raciocínio, gostaríamos de afirmar que o objetivo geral da mídia-educação pode ser resumido nos seguintes elementos: comunicação; busca de informação; percepção, análise e avaliação da produção profissional de mídia; produção, análise e avaliação da produção de mídia dos estudantes.

Dando continuidade à discussão sobre a definição de mídia-educação, enfatizamos a importância de uma abordagem ampla aos meios de comunicação e informação, uma abordagem que habilite crianças e jovens a se comunicar, buscar informação e usar diferentes mídias em diferentes contextos. Essa concepção ampla das mídias deve ser desenvolvida no sistema educacional em uma pesquisa transdisciplinar e considerada como um conceito dinâmico que constantemente reflita as correlações em que as mídias são incluídas, ou seja, conhecimento sobre: mídias e socialização (ensino informal); ensino de mídias, ou seja, sobre e com as mídias (ensino formal) e uso das mídias educacionais (ferramentas, programas e plataformas).

O desenvolvimento de amplas competências em mídia é central para que as pessoas consigam se comunicar, buscar informação, compartilhar conhecimento e usar os meios de comunicação de diferentes maneiras. Um conceito amplo de mídia deve ser implementado em todo o sistema educacional enquanto uma dimensão interdisciplinar da formação (VETTENRANTA, 2007).

\section{Educação e novas mídias/nova mídia-educação}

Talvez estejamos assistindo ao crescimento de um golfo entre os estilos de aprendizagem cultivados pela educação formal e aqueles que caracterizam as experiências extra-escolares das crianças. [...] Seria totalmente falso supor que os jovens já sejam usuários competentes dessas novas mídias ou que eles necessariamente já saibam tudo o que precisam saber. (BUCKINGHAM, 2003). 
Há muitos anos, na Dinamarca, estamos envolvidos na formação de professores para o ensino primário e secundário no campo da mídiaeducação (CHRISTENSEN; TUFTE, 2005). O objetivo desses projetos tem sido investigar a percepção e a compreensão que os alunos têm dos meios de comunicação e aumentar sua alfabetização midiática por meio de um método que combina produção e análise das mídias. Com o rápido desenvolvimento no campo das mídias e o crescente apagamento das fronteiras entre os meios tradicionais e os novos tornou-se necessário que a mídia-educação trabalhe com novas abordagens. Ainda assim, pensamos que a combinação entre produção e análise, num modelo em zig-zag, siga sendo um princípio indispensável, que descreveremos mais adiante. A produção e a análise devem ser desenvolvidas em uma relação de interação tanto quanto possível. Vemos o modelo em zig-zag como uma fonte de inspiração essencial para o desenvolvimento de conexões entre uso, produção e análise dos meios.

O modelo deve ser lido de baixo para cima e tendo em mente que os elementos centrais são a produção e a análise, em ação recíproca. Além disso, o que é chamado de "cânone midiático" opera quando os alunos assimilam conhecimento sobre a importância social e cultural dos meios. O modelo foi desenvolvido originalmente em uma época em que o acesso aos meios era menor do que hoje, quando era possível trabalhar intensivamente com um meio de cada vez.

Como foi dito, a cultura de hoje é multimídia - uma cultura das mídias Web 2.0, na qual a integração das imagens, sons, textos escritos e gráficos ocorre em ritmo acelerado. A cultura multimídia se caracteriza por suas qualidades interativas e pelo fato de que o usuário faz suas opções a partir de um grande material disponível. O desafio que essa forma cultural impõe à prática educacional é desenvolver um método capaz de abraçar todas essas expressões e gêneros.

Os elementos básicos do modelo em zig-zag são os seguintes: 


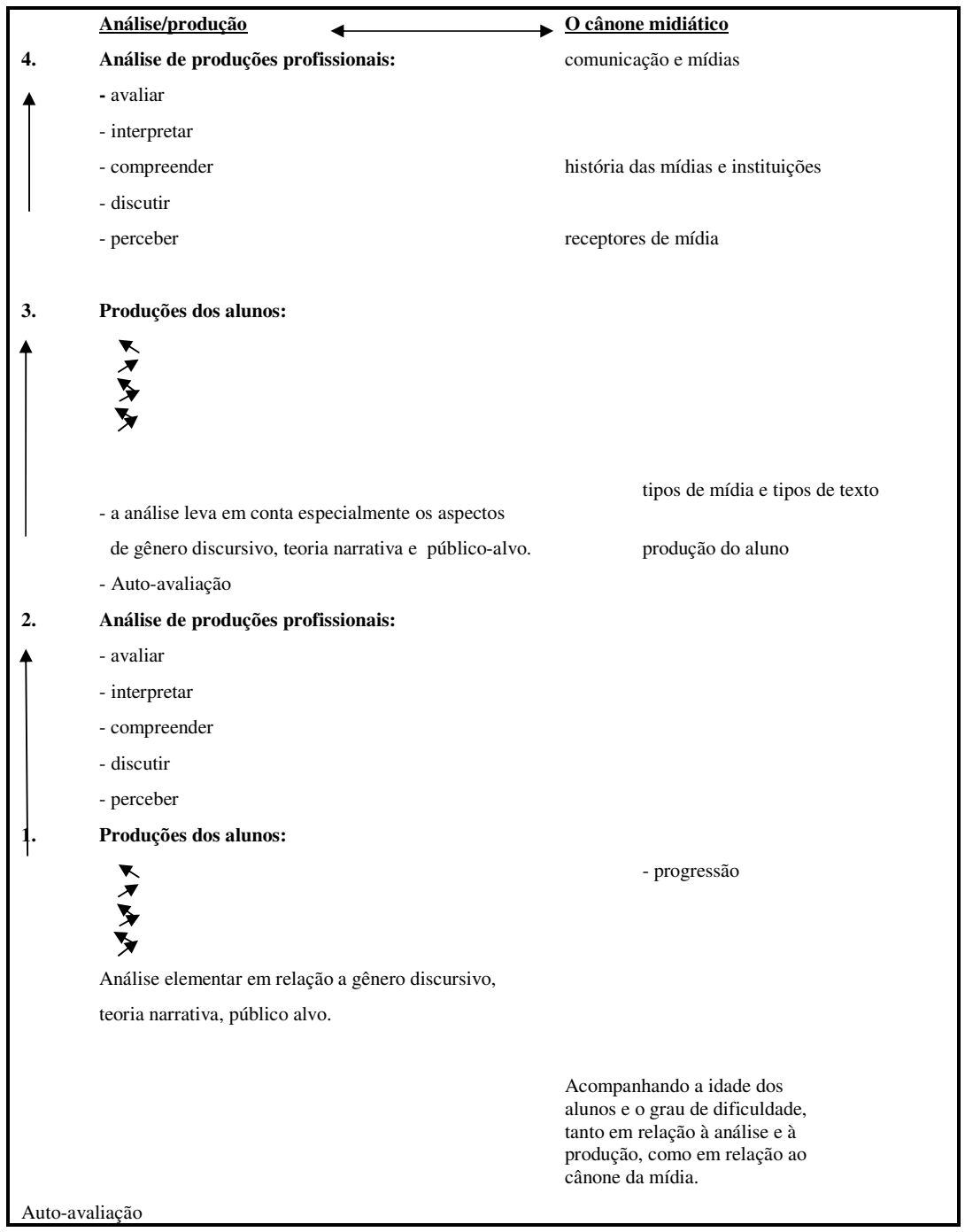

Figura 1 - Análise

Fonte: Tufte (1998, p. 179) 


\section{Exemplos de práticas}

Apresentamos a seguir exemplos de práticas em que, juntamente com sua educação continuada, os professores evoluem em seu conhecimento com relação à pedagogia das mídias. Essas práticas foram desenvolvidas por quatro professores que concluíram sua formação em educação em mídia e cinema no University College de Copenhagen e nesse contexto escolheram os temas com que iriam trabalhar: o cinema, em turmas de primeiro a terceiro ano do ensino primário, e o desenvolvimento de um "kit de cinema” para professores.

\section{Produção de filmes em classes de primeiro a terceiro ano do ensino primário}

Gitte Kokborg (2008), professora e bibliotecária escolar, observa que a produção de filmes está praticamente ausente nas classes de primeiro a terceiro ano (crianças de seis a nove anos de idade). O ensino baseia-se, ainda, principalmente em textos literários e o uso de filmes nas aulas volta-se principalmente para a literatura filmada, estudada a partir dos pressupostos literários. Gitte Kokborg teve uma formação que envolveu a produção de filmes, partindo daí para lecionar em classes de primeiro a terceiro ano do primário. Sobre esse contexto, ela diz:

As crianças de seis a nove anos gostam de falar frequentemente e por muito tempo sobre os filmes que veem e sobre quais elas acham melhores e piores... Os filmes é que causam as mais fortes impressões nas crianças, são eles que elas melhor relembram e aos quais mais se referem. A mesma tendência aparece quando elementos fílmicos são usados como fonte de inspiração para os trabalhos escritos. Isso significa que há uma diferença entre a relação das crianças com os filmes, e delas com os textos escritos. Consequentemente, enquanto escola precisamos discutir a mídia-educação como uma parte da educação fílmica onde, além de conhecimento técnico sobre o cinema, deve haver também o envolvimento da análise, da recepção, da estética e da experiência emocional. (KOKBORG, 2008). 
Em conjunto com sua reflexão sobre a prática, Gitte Kokborg (2008) trabalha com as quatro hipóteses a seguir:

- mesmo quando ainda muito novas em idade, as crianças podem e gostam de trabalhar com as mídias e possuem grande número de competências nesse campo;

- o conhecimento cotidiano das crianças sobre as mídias não é integrado às aulas. Como professores, precisamos reconhecer os conhecimentos das crianças e complementá-lo com o nosso;

- os professores têm receio de ensinar produção de filmes, particularmente nas turmas de primeiro a terceiro ano;

- as autoridades escolares devem estar envolvidas para que o desenvolvimento da mídia-educação seja uma responsabilidade da escola como um todo e priorizado como parte da cultura da escola.

Os planos de aula incluem a produção de animações, alternando a produção dos próprios alunos e o uso de recursos pedagógicos simples, como páginas na web e filmes. Os alunos são divididos em pequenos grupos de produção e o ponto de partida de todas as atividades são as experiências das próprias crianças com desenhos animados e filmes.

O curso no segundo ano é descrito assim:

- filmagem em stop-motion de coisas concretas, com duração de trinta segundos a um minuto. Por exemplo: "o lápis que escreve sozinho", "o lanche que desaparece mordida após mordida", "o relógio que anda super-rápido" etc.;

- o foco na tecnologia, na "competência com os botões", nos métodos (montagem etc.), na experiência da descoberta, na possibilidade de fazer coisas que na vida real são impossíveis (em termos de tempo, lugar, habilidade física etc.), no recorte de imagens, entre outras experiências gerais a partir de filmes;

- o filme é montado, mas sem o som. Mais tarde, os estudantes escolhem uma música que vão tocar no momento da apresentação, seja num aparelho de som ou em instrumentos ao vivo (para fazer efeitos de som, por exemplo). Desse modo, os alunos vão adquirindo noções de história do cinema - como o cinema mudo, onde o som era tocado "ao vivo" durante a exibição. As 
crianças trabalham em grupos de três e a duração do curso é de aproximadamente 12 aulas.

Depois de cumpridas as etapas do curso, a professora concluiu o seguinte:

- naturalmente as crianças do primeiro ao terceiro ano não são capazes de produzir filmes longos, nem é esse o objetivo. Essa faixa etária trabalha frequentemente com materiais concretos, uma vez que sua capacidade de pensamento abstrato ainda não se encontra plenamente desenvolvida. Além disso, elas acham difícil ficar um longo tempo concentradas, sentadas na cadeira, o que não significa, porém, que não sejam capazes de se deixarem absorver por uma tarefa. O fato de que as mídias ocupam grande parte do tempo de lazer das crianças e influenciam a formação de sua identidade é uma razão especial para o planejamento de aulas de cinema onde os alunos produzam filmes eles mesmos, alternando essa atividade com discussões mais teóricas e visuais sobre o cinema;

- em minha opinião, um dado concreto será apropriado de forma mais adequada se for apresentado de diferentes maneiras, envolvendo aspectos visuais, táteis, teóricos e práticos sempre que possível. O foco dessa educação é evidentemente o processo, mas acredito que o produto final é parte importante do processo;

- vejo a dimensão da produção de dois modos, com um conteúdo diferente, sendo ambos necessários para que se alcance uma mídiaeducação de qualidade. De um lado, o que está em jogo são os processos de aprendizado estético, tais como a oportunidade de expressão, a compreensão dos códigos culturais ligados às mídias; do outro, o que é aprendido são os processos em si. O mais importante na mídia-educação é que os alunos vejam a si mesmos como usuários ativos das mídias, criadores e produtores de sentidos que por meio de reflexão, comunidade, compreensão cultural, percepção crítica, partilha de conhecimentos e colaboração, têm a possibilidade de adquirir influência sobre suas próprias vidas. (KOKBORG, 2008) 


\section{O “kit cinema" - uma ferramenta para o professor}

Ao trabalharmos com as novas plataformas de mídia e considerando as possibilidades da Web 2.0 na educação, o modelo zig-zag pode ser desenvolvido ainda mais, em um "modelo tufão" - descrito como zig-zag 2.0. Esse modelo foi desenvolvido por três professores, Andreas Binggeli, Christina Blomquist Jørgensen e Lasse Remmer, também ligados aos estudos de mídia e cinema no University College de Copenhagen. Em um trabalho acadêmico, eles desenvolveram um "kit cinema" (film tool kit) baseado em suas experiências de ensino com crianças de diferentes idades.

Palavras-chave ligadas a ele são progressão, re-midiação (re-mediation) e integração de mídias. Os três professores dizem:

A progressão numa situação de aprendizagem é sempre desejável. Os alunos devem adquirir novas habilidades e serem desafiados de forma a que tenham constantes oportunidades de desenvolvimento. O problema da midia-educação hoje em dia é exatamente este desafio. Hoje, as crianças e os adolescentes não apenas usam as midias - eles são parte das mídias [...] Se for possivel utilizar as competências que eles adquirem na "escola paralela dos meios de comunicação" e combiná-las com o conhecimento e as competências pedagógicas dos professores, isso fornecerá uma plataforma de partida para a progressão. O termo "remidiação" liga-se intimamente ao termo "convergência midiática".

A "remidiação (re-mediation) descreve as estéticas e os modos de expressão desenvolvidos quando as midias convergem. Por exemplo: o tocador de mídia em um iPhone da Apple tem a aparência de um tocador de DVD, lembrando alumínio fosco, polido, com um botão "play" em forma de triângulo - exatamente como em um iMac. A remidiação ocorre quando uma midia toma a forma e a estética de outra e a recria. O que fazemos, como professores, com todas essas possibilidades de integração das midias? Temos que comecar por pensar em "escola" e entender nosso trabalho como professores de uma forma nova.

Como mencionamos anteriormente, um importante elemento de nosso "kit cinema" é a possibilidade de criar progressão na mídia-educação. Acreditamos que os modelos em zig-zag de Tufte e Christensen são adequados para essa progressão quando o foco está na análise e na produção. Mas falta produção às escolas públicas hoje, e esta questão é central para nós. Nosso pressuposto é o "aprender fazendo". Concordamos que mesmo que as crianças e os jovens sejam hoje grandes usuários tecnológicos das mídias (incluindo o cinema) em seu cotidiano, isso não significa que sejam também lúcidos e críticos. 
Considerando que as imagens em movimento desempenham um papel ainda maior na vida das crianças, é essencial desenvolver e criar um solo fértil para um ensino de qualidade por dentro das midias e com a ajuda delas. No entanto, queremos repensar os modelos - propondo uma versão 2.0, ou "modelo tufão". O modelo original em zig-zag tem a ver com a alternância entre a produção e a análise, e entre a produção própria e a produção profissional. Nosso modelo é circular e seu ponto de partida é sempre a produção própria.

Nós imaginamos um modelo mais detalhado que leva em conta a organização das aulas, o papel do professor etc. Ao imaginarmos a producão no "kit filmes" acreditamos que mais alunos estão sendo considerados em relação à progressão e diversificação.

No modelo abaixo existe uma alternância entre a aprendizagem formal em sala de aula e a aprendizagem informal, aquela que ocorre no

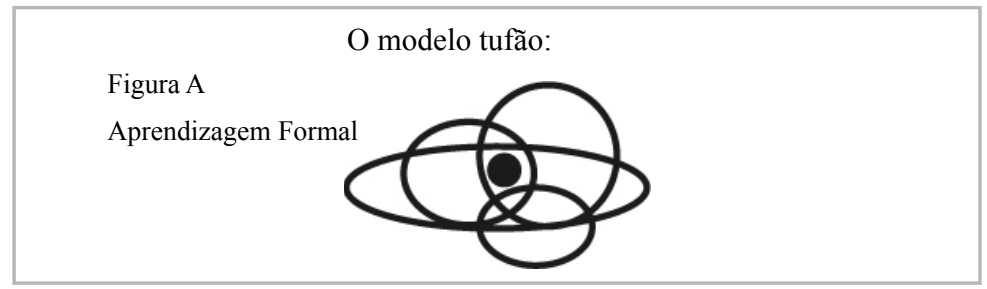

Análise Produção

Figura A: $\mathrm{O}$ modelo visto do alto

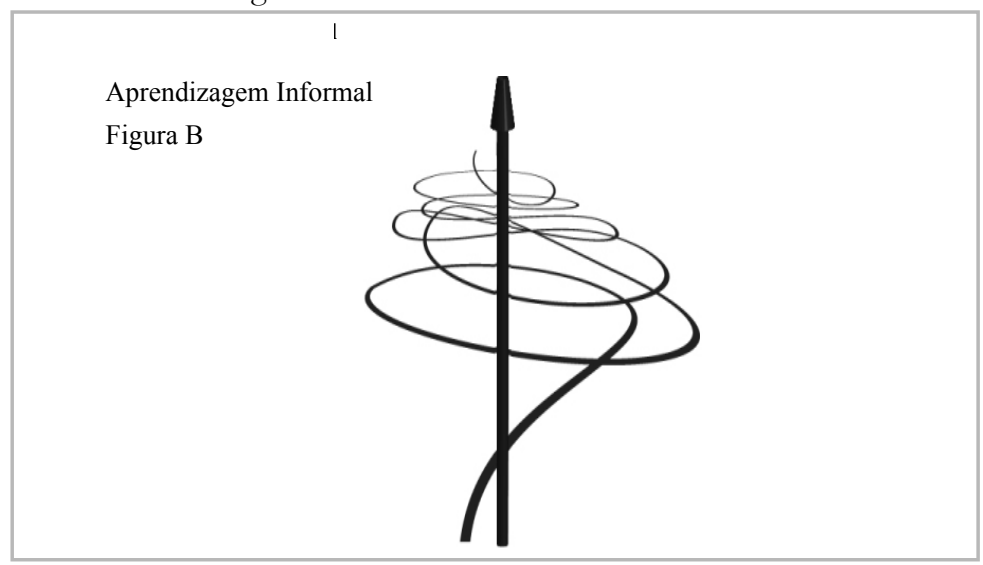

Progressão

Figura B: O modelo visto de lado

Fonte: Binggeli; Jørgensen; Remer, 2008. 
tempo de lazer. Pode também haver alternância entre a educação orientada pelo professor, no caso de conteúdos específicos ligados aos filmes, e uma educação experimental não dirigida, na qual os estudantes elaboram as regras por si próprios. Um dos pontos fracos do modelo em zig-zag original é a progressão linear que determina que só se pode seguir para B quando se tiver dominado A. Pensamos que a progressão deveria ocorrer de forma circular para que se pudesse retornar a criações anteriores e desenvolver conteúdos e conhecimentos trabalhados previamente. (BINGELLI; JØRGENSEN; REMER, 2008).

\section{O futuro}

A mídia-educação tem tido altos e baixos nos últimos anos, mas se compararmos o presente com a situação de dez anos atrás encontraremos algumas diferenças. O panorama hoje envolve mais mídias, no contexto de uma crescente globalização e comercialização. Os processos tecnológicos no campo das comunicações desenvolvem-se de forma cada vez mais acelerada. Hoje é a Web 2.0 e logo será a $W e b$ 3.0, com a disponibilização de novas plataformas de mídia e comunicações.

Consequentemente, uma questão fundamental é como ocorrerá a disseminação das mídias e como será o acesso a elas. Haverá no futuro uma disparidade ainda maior no que se refere às condições das crianças e dos jovens em relação às mídias? Nesse contexto, a habilidade crítica, a participação e o compromisso serão parâmetros importantes? Haverá mais crianças analfabetas digitais à medida que as mídias se desenvolvem ainda mais?

As crianças de hoje têm sido consideradas inovadoras em relação às novas mídias. Em grande parte, concordamos com essa visão, já que elas são “especialistas em teclado" e usuárias competentes das mídias. No entanto, falta a elas uma compreensão cultural profunda das mídias e ferramentas para interpretar o cenário internacional das mídias comerciais, bem como da cultura midiática cotidiana; essas são habilidades que o professor tem responsabilidade de comunicar e é aí que se evidencia a necessidade da mídia-educação, bem como a necessidade de que os professores tenham competências relevantes nesse campo. 
Um conceito central para a mídia-educação é o de progressão. Deveria ser desenvolvido um modelo para a integração das mídias, a fim de que elas possam apoiar e desenvolver as atividades acadêmicas, mas ao mesmo tempo desafiar a agenda acadêmica. A integração das mídias demanda uma ligação entre a progressão acadêmica e progressão midiática. Desse modo, precisamos assegurar que: haja uma relação entre a progressão do desenvolvimento das mídias e a da educação; haja uma redefinição das didáticas na mídia e na academia; os meios digitais desafiem a agenda educacional.

A cultura das mídias na vida cotidiana precisa ser integrada ao currículo escolar, apoiando o desenvolvimento das práticas pedagógicas em mídiaeducação. Além dos termos já mencionados - "perspectiva crítica", "análise" e "prática", outros termos importantes são "produção" e "criatividade". As perspectivas que ambos contemplam são centrais e em relação à mídiaeducação a "produção" é um foco extremamente importante.

Como foi enfatizado, trata-se de uma tarefa adulta - especialmente nas escolas - aceitar e explorar o uso de mídias entre as crianças, qualificando os estudantes para serem lúcidos e perceptivos em seu uso das mídias. Ao mesmo tempo, enquanto adultos, devemos observar os modos como o uso de mídia no tempo de lazer pode contribuir para colocar em questão o programa educacional e romper tradições sobre o que é a aprendizagem. Isso pode ocorrer tanto em relação às atividades acadêmicas quanto aos projetos transdisciplinares, devendo ser um objetivo explícito da escola trabalhar mais profundamente com as mídias e qualificar as habilidades profissionais das crianças, fortalecendo suas competências analíticas.

Em resumo, isto significa que a plataforma de lançamento para agregar prioridade à mídia-educação é a capacidade de os professores qualificarem os alunos na direção de uma utilização excelente das possibilidades das mídias, a fim de que eles possam se desenvolver como cidadãos verdadeiramente democráticos em uma sociedade dominada pela economia de mercado. No entanto, isso faz emergir diversas questões: de que modo o uso que as crianças e os jovens fazem das mídias em seu tempo livre pode desafiar o trabalho escolar? Como podemos acompanhar a experiência das crianças e dos jovens com as midias e em que ela consiste? Como podemos levar as experiências das crianças e dos jovens para a sala 
de aula? Que processos mídia-educacionais precisam ser desenvolvidos na escola? Que competências os professores devem desenvolver para integrar as mídias ao ensino? Que tipos de papéis os professores e supervisores deveriam desenvolver nesse sentido?

Essas questões são certamente importantes, embora difíceis de responder, e esperamos ter contribuído para possíveis respostas.

Várias discussões têm ocorrido recentemente em relação ao "nome do bebê", ou seja, à designação mais adequada de nosso campo de estudo. Considerando o fato de que as estratégias mercadológicas desempenham importante papel em relação às novas mídias, tem se argumentado que os estudantes também deveriam aprender alguma coisa sobre economia, consumo, marketing etc. (TUFTE, 2007).

Então, como deveríamos chamar esse campo? Mídia-Educação? Alfabetização Midiática (Media Literacy)? Alfabetização Digital (Digital Literacy)? Alfabetização para a Internet (Internet Literacy)? Educação em Mídia e Consumo? Educação em Mídias e Economia? Ou deveríamos chamá-la pelo nome que aparentemente é o mais aceito, a julgar-se pelas discussões no grupo de trabalho em Mídia-Educação da IACMR: Educação para a Alfabetização Midiática (Media Literacy Education)?

É sempre difícil prever o futuro e, neste caso, é difícil prever se a mídia-educação num sentido amplo conseguirá afirmar-se seriamente, mas esperamos sinceramente que isso aconteça.

\section{Nota}

1 N.T.: O termo literacy, usado no texto original, poderia ser traduzido como literacia. Como, porém, esse termo é pouco corrente no português brasileiro, por razões de fluência optamos neste artigo pelo termo alfabetização. Observe-se, porém, que o sentido original da metáfora literacy no contexto da mídia-educação envolve tanto a aprendizagem dos códigos como seus usos sociais, o que corresponderia a uma alfabetização conjunta com o letramento.

\section{Referências}

BINGGELI, A.; JORGENSEN, C. B; REMER, L. Filmvarktojskassen: en mediefaglig førstehjælpskasse. PD-opgave i Mediepædagogik, Film- og 
medieuddannelsen 2007. Copenhagen: Upubliceret eksamensopgave/ University College, 2008.

BUCKINGHAM, David. Media education, learning and contemporary culture. Cambridge: Polity Press, 2003.

BUCKINGHAM, David; WILLETT, Rebekah (Org.). Digital generations: children, young people and new media. London: Lawrence Erlbaum Associates Publishers, 2006.

CHRISTENSEN, Ole; TUFTE, Birgitte. Skolekultur mediekultur: modspil eller medspil? København: CVU København og Nordsjællands Forlag, 2005.

DANMARKS NATIONALLEKSIKON A/S: Den Store Danske

Encyclopaedi, 2009. Disponível em: < http://www.denstoredanske.dk/>. Acesso em: 9 out. 2009.

EKSTRÖM, K.; TUFTE, Birgitte (Org.). Children, media and consumption. Göteborg: Nordicom/Göteborg University, 2007.

ERSTAD, Ole. Digital kompetanse i skolen: en innføring. Oslo: Universitetsforlaget, 2005.

INTERNATIONAL ASSOCIATION FOR MEDIA AND COMMUNICATION RESEARCH. IAMCR 2008 World Congress, Estocolmo. Anais... Estocolmo: IAMCR, 2008. Disponível em: <http:// www.mediaandglobaldivides.se/>. Acesso em: 28 maio 2009.

KOKBORG, Gitte. Filmproduktion i indskolingen: PD-opgave i

Mediepædagogik, Film- og medieuddannelsen 2007. Copenhagen: Upubliceret eksamensopgave/University College Copenhagen, 2008. LIVINGSTONE, Sonia; BOBER, M. Bober. UK Children go Online. London, instituição? Department of Media and Communications, London School of Economics 2005. Relatório de Pesquisa. Disponível em: <http:// www.citizensonline.org.uk/site/media/documents/1521_ UKCGO-final-report.pdf>. Acesso em: 28 maio 2009.

NORRETRANDERS, Tor. Civilisation 2.0. Copenhagen: Thanning \& Appel, 2007. 
QVORTRUP, Lars. Knowledge, education and learning: e-learning in the knowledge society. Frederiksberg: Samfundslitteratur Press, 2006.

TUFTE, Birgitte. Skole og medier. Copenhagen: Akademisk forlag, 1995. . Born, medier og marked. Frederiksberg: Samfundslitteratur, 2007.

TUFTE, Birgitte et al. Frontrunners or copycats. Copenhagen: CBS Forlag. 2005.

VETTENRANTA, S. (Org.). Mediedanning og mediepedagogike.. Oslo: Gyldendal Akademisk, 2007. 


\section{Media-Education - between theory and practice}

\section{Abstract:}

The article first focuses on the current discussion about the definition of media-education using references from a recent international conference. There are currently interesting perspectives about media and children. Media technologies change quickly, as does the use that children make of them, which provides them abilities that the previous generation did not have. This challenges the form and content of media education, as well as the entire school curriculum. This article discusses a broad educational approach, which is both theoretical and practical, to the theme of media and information. It is based on the authors' cooperative experiences with teachers from the Danish school system. Two models are presented: the first, which has been used for many years in relation to traditional media, such as newspapers, TV and video - is called the zigzag method. The second is aimed at teaching in the new multimedia context. The first describes teaching about film in the 1 st-3rd grades of elementary school and the second describes the development of a film tool for teachers, including what the authors call the "typhoon model," a second version of the zigzag model. The article concludes with a discus-

\section{Educación Mediática - entre la teoría y la práctica}

\section{Resumen:}

El artículo focaliza las discusiones actuales sobre la definición de educación mediática, refiriéndose a una reciente conferencia internacional. Hoy contamos con perspectivas interesantes en relación a los medios de comunicación y los niños y niñas. Las tecnologías de los medios cambian rápidamente, así como el uso que los chicos hacen de ellas, otorgándoles habilidades que la generación anterior no tenía. Esta cuestión desafía la forma y el contenido de la educación mediática así como al currículo escolar. El artículo discute un abordaje teórico-práctico en relación al tema de los medios y de la información. Parte de la experiencia de cooperación de los autores con profesores del sistema escolar danés, presentando dos modelos: el primero, que fue usado hace muchos años en relación a los medios de comunicación tradicionales, como los diarios, la televisión y el video - el llamado modelo zig-zag. Y el segundo, direccionado a la enseñanza en el nuevo contexto de la multimedia. El primer proyecto describe cómo enseñar sobre cine en las aulas del primer al tercer año de la educación básica, y el segundo describe el desarrollo de una herramienta de cine para profesores, incluyendo lo que los autores llaman de "modelo ciclón”, una segunda versión del mo- 
sion about the future of media-education.

Key words: Media. Educational Technology. Education - Technological Innovations. delo "zig-zag". El artículo concluye con una discusión sobre el futuro de la educación mediática.

Palabras-clave: Educación Mediática. Tecnología educacional. Educación. Innovaciones tecnológicas.

\section{Birgitte Tufte}

Copenhagen Bussiness School, Solbjerg Plads 3C, DK-2000, S Frederiksberg, Dinamarca. Tel.: +4538152169

E-mail:bt.marktg@cbs.dk

\section{Ole Christensen}

University College Copenhagen

Titangade 11. Zip 2200, Copenhagen N, Dinamarca

E-mail:oc@cvukbh.dk; ole.christensen@skolek.dk

\section{Tradução Gilka Girardello}

Departamento de Metodologia de Ensino, $1^{\circ}$ andar/ Bloco B, CED/UFSC

Campus Universitário, Trindade

CEP: 88040-900

Florianópolis, SC

E-mail:gilka@floripa.com.br 